\title{
Una inspección sin resultados. La visita judicial y hacendística del Perú (1664-1696)
}

\section{An inspection with no results. The judicial and fiscal visit of Peru (1664-1696)}

Ismael Jiménez Jiménez ${ }^{1}$

Universidad de Cádiz

\section{Resumen}

A lo largo del último tercio del siglo XVII, la situación política y fiscal del distrito de la Audiencia de Lima hizo necesaria que el Consejo de Indias ordenase la puesta en marcha de un proceso de visita. Las autoridades metropolitanas acordaron la división de esta tarea en dos partes, una judicial y otra hacendística, pero los resultados positivos no se produjeron en ningún momento, ni tan siquiera en sus inicios. Así, ante la falta de conclusiones, el proceso se fue alargando, pasando de

1 Profesor ayudante del área de Historia e Instituciones Económicas de la Universidad de Cádiz.

Doctor con mención internacional y premio extraordinario por la Universidad de Sevilla.

Código ORCID: 0000-0002-1679-9334

Contacto: ismael.jimenez@uca.es / ijimenez5@us.es 
manos de unos visitadores a otros con idénticos rendimientos, sin que se produjesen modificaciones procesales para su mejora. De esta manera, cuando se dio por concluida la visita, el estado en que se encontraban las instituciones sujetas a la auditoría apenas se diferenciaba del detectado al inicio de la inspección.

Palabras clave: visitas, inspecciones fiscales, Audiencia de Lima, Real Hacienda, instituciones fiscales virreinales, siglo XVII.

\section{Abstract}

Throughout the last third of the XVII century, the political and fiscal situation of the Audience of Lima district made it necessary for the Consejo de Indias to order the implementation of a visita process. The metropolitan authorities agreed to divide this task into two parts, one judicial and the other one related to the treasury, but the positive results didn't occur at any time, not even in its beginning. Thus, in the absence of conclusions, that process was lengthened, passing from one inspector to another with identical performance, without procedural changes for its improvement. In this way, when the visita was concluded, the status of the institutions subject to the audit was hardly different from that detected at the beginning of the inspection.

14 Key words: visitas, viceregal fiscal inspections, Audience of Lima, Royal Treasury, fiscal institutions, XVII century

Los procesos de visita y juicios de residencia se han tenido durante mucho tiempo como métodos ejemplares de control de la administración indiana. Sin embargo, el crecimiento 
de los estudios sobre estos mecanismos, en todas las épocas y regiones americanas con presencia hispánica, ha puesto en duda aquella afirmación como única e inalterable. Hoy, sabemos que estas herramientas diseñadas en la península ibérica tuvieron que ser retocadas para aplicarlas en América y que su eficacia no fue siempre la misma.

En las siguientes páginas propongo articular, desde una primera base teórica, un relato sobre la visita a la que fueron sometidos varios organismos de la jurisdicción de la Audiencia de Lima durante la segunda mitad del XVII y cuyos resultados no fueron tan satisfactorios como se esperaban. Los fondos conservados en el Archivo General de Indias permiten reconstruir más de tres décadas de auditoría y ahondar en las personalidades encargadas de verificar el funcionamiento de las instituciones peruanas.

\section{Los métodos de control administrativo: una sujeción relajada}

Tras el asentamiento de la dominación hispánica en las Indias, se configuró una estructura administrativa dotada de mecanismos metropolitanos para conservar un alto grado de control sobre el gobierno de territorios tan alejados: las visitas y los juicios de residencia. Pasada la primera centuria de presencia española, estas inspecciones fueron desvirtuándose progresivamente debido a que, entre otras razones, los sujetos encargados de llevarlas a cabo coincidían en muchas ocasiones con el nuevo titular de la plaza auditada. Por este motivo, las demandas contra el mal gobierno se redujeron, ya que nadie se arriesgaba a perder el favor del nuevo funcionario. Además, los individuos provistos evitaban sancionar a su antecesor para así heredar sus estructuras ejecutivas. Pero 
también se buscó no crear una suerte de jurisprudencia ${ }^{2}$ para que, acabado el ejercicio del inspector, pudiese aplicársele a sí mismo (Lohmann Villena,1957, p. 471). Por ello y por otras causas que iré apuntando, el aparato de control metropolitano sobre la administración americana se fue diluyendo durante el siglo XVII.

Buena parte de la responsabilidad de que esta cadena de comprobaciones sobre el gobierno en el Perú se rompiese en todos los niveles, se debió a la inadecuada correlación entre salarios y precios. Dicha ecuación ha sido señalada como uno de los fundamentos que explican la corrupción ${ }^{3}$ acaecida en el virreinato por parte de los empleados de la Corona. Como indica John Phelan, los oficiales virreinales estuvieron durante el XVII a caballo entre el funcionariado patrimonial, dueños del empleo y retribuidos en especie y sobresueldos, y el funcionariado moderno, que acorde con las nuevas formas de administración y pensamiento económico, no era más que un trabajador a cargo de la Corona, con pagas periódicas en metálico (1995, p. 479). El oidor, fiscal, alcalde del crimen, contador, oficial real, corregidor, entre otros, que ocupó una plaza en las estructuras gubernativas peruanas de ese siglo no

2 No hay que perder de vista las particularidades que tuvo el derecho indiano. En este sentido, el orden jurídico americano se componía de la ley, la costumbre y la doctrina de los juristas, pero no existía una prelación clara ni una primacía de una fuente sobre otra (Smietniansky, 2007, p. 77).

3 Se debe remarcar que el término "corrupción" es perfectamente válido a la hora de hablar de desviaciones desde el poder público hacia intereses privados individuales o grupales durante los siglos XVI, XVII y XVIII. El concepto fue empleado por los contemporáneos y en él se englobaron muchas de las prácticas que su definición es capaz de recoger. Sobre esta cuestión son aclaradoras las palabras de Ponce Leiva (2016, pp. 193196). 
dejó de combinar esas tipologías y, para adecuar su retribución al nivel de vida deseado, muchos buscaron nuevas vías de ingresos.

En cualquier caso, no debe pensarse que la totalidad de los inspectores nombrados por la Corona o las audiencias se decantaron siempre por ocultar los desmanes y corrupciones que descubrían en las auditorías. Algunos encargados de estas investigaciones, motivados por enemistades, venganzas o un paradójico deseo de reestablecer el imperio de la ley, actuaron severamente para destapar las corruptelas que se cometían en las demarcaciones analizadas. No obstante, para evitar que las malas pretensiones de jueces o visitadores estorbasen la justicia de manera prevaricadora, se permitió que los inspeccionados pudiesen comunicarse con la corte y se otorgó un amplio espacio para el recurso y la protesta contra las indagaciones sufridas y los cargos interpuestos (Céspedes del Castillo, 1946, p. 1010).

Papel fundamental en los juicios de residencia y en las visitas de control administrativo fue el representado por los testigos. Fuente primaria y fundamental para los inspectores, las declaraciones prestadas por estos individuos fueron la base, junto con las pruebas documentales, para demostrar corrupciones o malas prácticas. Así, los declarantes también variaron en razón de la naturaleza de la inspección, pues no testificaban las mismas personas en las auditorías de un corregimiento andino que en la de un virrey. Cuando se trataba de inspeccionar lo cometido por ministros de alto estatus, los sujetos testificantes solían pertenecer a las élites locales: oficiales reales, capitulares, eclesiásticos, mercaderes o vecinos con reconocimiento público (Herzog, 1997, p. 820). Por ello, las opiniones vertidas revelaban cuál era la consideración de lo más granado de la sociedad hacia el funcionario inspeccionado o sobre la institución auditada. 
Sin embargo, las informaciones aportadas por estas personas no siempre fueron útiles para las inspecciones. Muchas eran rutinarias y fruto de interrogatorios preparados de antemano, sobre los cuales cabía poco albedrío. Esto explica que algunos juicios de residencia o visitas fracasaran casi desde el inicio, pues algunos declarantes eran inválidos si se buscaba mantener cierto control sobre los cargos o instituciones observadas. Así, destacaron quienes sí fueron capaces de contestar las preguntas, aportando detalles sustanciosos que coincidieron con lo replicado por otras personas ante la misma inquisición. Cuando eso se produjo, el juez encontraba un filón y el inspeccionado comenzaba a buscar argumentos legales para defenderse de los posibles cargos en su contra. Sin embargo, también se dieron testimonios contradictorios que ayudaron a esta herramienta inspectora (Jiménez Jiménez, 2015, p. 63). Al ocurrir ello, el pesquisidor debía confrontar a los testigos antes de redactar los cargos. Una tarea complicada que, además, debía realizar con el tiempo suficiente como para que las pruebas no fuesen adulteradas ni eliminadas (Mariluz Urquijo, 1952, p. 185).

De una forma o de otra, lo cierto fue que el mecanismo de visitas y juicios de residencia no funcionó correctamente durante la segunda mitad del siglo XVII en ningún nivel de la administración. Por ejemplo, en 1698 se detectó en el dis-

18 trito de Cuzco que estaban pendientes de tramitarse hasta cincuenta y cinco procesos de residencia contra otros tantos corregidores, lo que no fue problema para impedir sus sucesiones desde 1681 (Lohmann Villena, 1957, p. 484). Como indica Sánchez Bella, las deficiencias que lastraban las visitas fueron detectadas por sus contemporáneos, es decir, las alteraciones de los equilibrios políticos, los grandes costos supuestos para la Real Hacienda, su prolongación en el tiempo 
y los paupérrimos resultados que de ellas se obtenían (1950, p. 388). Ante este paisaje, puede entenderse que Madrid y Lima habían fracasado en sus deseos de mantener un gran control y supervisión sobre la administración americana. Los aparatos articulados en torno a los juicios de residencia y las visitas estaban invalidados. El dominio y la dirección que desde la península ibérica se podía dar al gobierno de las Indias cada vez se hizo más difícil. Tres afirmaciones que, aun considerándolas ciertas, obvian otra cuestión fundamental, como es el hecho de la negociación política entre las jerarquías a un lado y otro del océano. Así, podemos entender que el relajamiento de los medios de control también fue motivado por cierto grado de tolerancia hacia la corrupción, que fue disimulada como útil mediación entre los poderes metropolitanos y los indianos (Ponce Leiva, 2016, p. 197).

Pese a ello, en la segunda mitad del XVII, el Consejo de Indias nunca pensó en suprimir estos sistemas de control. Todo lo contrario, los consejeros apostaron por continuar enviando visitadores y residenciadores, aunque el principal objetivo de los primeros fuese la supervisión de la Real Hacienda (Escobedo Mansilla, 1986, p. 13). He aquí el leitmotiv de las visitas en este período. El conocimiento específico y minucioso del estado de las contabilidades de las cajas reales fue entendido como el principal instrumento para eliminar cualquier tipo de corruptela. Así, tras dirigir los asientos impositivos, las políticas mineras y ciertos asuntos de indígenas, la contaduría del consejo se volcó en el despacho de visitadores que limitasen las prácticas corruptas en la administración (Andrien, 2011, p. 110).

Pero la visita al modo peninsular requirió retoques para ser aplicada en las Indias. La principal de estas singularidades se 
debe a la irregularidad de estas inspecciones, pues por su escasa periodicidad escapaban a la visita corregidores y virreyes. Para ellos funcionaba otro mecanismo de control: el juicio de residencia. No obstante, se debe apuntar que todos los empleados por la Corona estuvieron obligados a pasar por este proceso tras finalizar sus ejercicios.

El juicio de residencia nunca fue un trago agradable, especialmente para los virreyes, a quienes les resultó complicado la composición con el pesquisidor. Tal fue así, que hubo incluso quienes buscaron esquivarlo. El duque de la Palata, virrey del Perú entre 1681 y 1689, en su relación de gobierno al conde de la Monclova rescató un discurso del conde de Chinchón (1629-1639) para suprimir las residencias. Palata consideraba que estas auditorías de gobierno eran casi ofensivas, sobre todo por el riesgo de que el juez pudiese valerse de testigos calumniosos para imputar delitos a un virrey. Las palabras del duque son fiel prueba de ello: "lo cierto es que quien representa la persona de S.M. conviene que tenga entera autoridad y que no pueda estar sujeto a un riesgo de tanto descrédito para su decoro" (Hanke y Rodríguez, 1980, p. 72). Aun así, Palata y el resto de virreyes eran conscientes de que solo la permanencia de los juicios de residencia podía mantener a los funcionarios con más o menos sometimiento a la Corona. Por ello, este "sistema de responsabilidad gu-

20 bernativa y de control" (Lohmann Villena, 1957, p. 464), a pesar de ser poco eficiente durante la segunda mitad del seiscientos, creó ciertos reparos en los empleados reales y estableció fronteras entre las corrupciones "toleradas" y las que no estaban permitidas.

El gran temor de los virreyes respecto a las residencias estaba en que ellos se marchaban, pero los magistrados de la $\mathrm{Au}$ - 
diencia permanecían en Lima con capacidad de maniobrar de forma vengativa contra ellos. No debe olvidarse que, al contrario que las visitas, estos juicios eran encomendados por regla general a un oidor, alcalde del crimen o fiscal del tribunal, lo que causó temores a todo alter ego, pues hay que tener en cuenta la polarización de la chancillería durante cada gobierno. Así, cualquier virrey sopesó reducir su autoridad de motu proprio para sustituirla por tolerancia y mano izquierda con los togados, una decisión inteligente y con miras futuras para evitar padecer una tortuosa residencia (Lohmann Villena, 1974, p. 19). Esta postura tomada por los virreyes les favorecía claramente, pero a su vez incidía en el descrédito de los propios juicios de residencia. Aquellos jueces que habían sido favorecidos por el virrey de turno no procedieron con todo el peso de la legislación indiana contra ellos, es decir, una actuación prevaricadora a toda luz.

Así pues, el sistema para auditar a los empleados de la Corona en las Indias estaba fallando durante el siglo XVII y de ello fueron conscientes tanto en el Perú como en la metrópoli. En 1621, el fiscal Enríquez planteó abiertamente este fracaso, aunque sin aportar ninguna reforma. Para este magistrado, constituía un error encomendar las residencias al sujeto provisto para suceder el oficio, ya que ello, en su opinión, era "enviar un discípulo a que se componga con el maestro". El fiscal argumentó que estos no tardaban mucho en entablar conversaciones con los corregidores u otros empleos a quienes estaban investigando para establecer una cuantía previa a las pesquisas y así disimular en mayor o menor medida los delitos y corruptelas que hallasen (Lohmann Villena, 1957, p. 481). Es decir, la composición era inevitable, fuese quien fuese el sujeto encargado de llevar a cabo el juicio de residencia. Para el fiscal Enríquez, lo único que variaba era el valor 
monetario de esta prevaricación y cohecho: a más desmanes cometidos, mayor hubo de ser lo pagado por el residenciado al residenciador. En este sentido, se puede afirmar que la condescendencia practicada por algunos jueces se convirtió en ejercicio habitual, casi tradicional. Así, la composición puede encuadrarse como uno de aquellos fenómenos que Tau Anzoátegui señaló como permitidos por los magistrados, aun siendo contrarios a la legislación (1986, p. 379).

Aunque el sistema se constató como inútil, ni desde Madrid ni desde Lima se formularon mecanismos novedosos para mantener cierta coerción legal hacia los servidores de la Corona, controlar sus actividades en los diferentes escalones de la administración y, entre otros objetivos, evitar abusos contra los naturales y contra la Real Hacienda. En cualquier caso, durante la segunda mitad del XVII las visitas habían quedado configuradas por una serie de rasgos propios y característicos.

\section{Las características de las auditorias institucionales: la visita}

En cuanto a las visitas, la ejecución de una inspección de este calibre en el Perú siempre necesitó cierto grado de secretismo, aunque en la práctica se conocieran todos los detalles, incluso antes de que arribase su encargado. Esta característica fue ineludible, puesto que ello daba al provisto como juez capacidad para garantizar la seguridad de las personas interrogadas. Esto era clave para obtener respuestas, pues de otro modo se esperaban venganzas de los acusados una vez que el visitador hubiese acabado su tarea (Céspedes del Castillo, 1946, p. 989). Tampoco se debe olvidar que las posibles denuncias se enmarcaban dentro de los juegos políticos habi- 
tuales para presionar a los poderes (Andújar Castillo, Feros y Ponce Leiva, 2017, pp. 294-295). Sin embargo, esta misma amplitud de maniobra otorgada a los visitadores y los síntomas de ineficacia fueron los culpables de que el Consejo de Indias -tan interesado en estas inspecciones cuando estaban ceñidas a materias fiscales- comenzara a revelar dudas sobre la validez de las visitas. Así, el conde-duque de Olivares llegó a proponer, como medida reguladora, que las auditorías se efectuasen una vez cada cinco años en las Audiencias y no cuando a los consejeros les pareciese oportuno o las denuncias procedentes de determinadas jurisdicciones aconsejaran su puesta en marcha. Además, el valido de Felipe IV también planteó que no podían usarse como testigos en las visitas, ni en las residencias, a sujetos que hubiesen servido corregimientos, pues por su corto salario eran considerados propensos a los negocios ilegales y otras corruptelas. Estas sugerencias de Olivares concluyeron adelantando aquello en que se convirtieron residencias y visitas si no se implantaban reformas inmediatas: un trámite de control que se transformaría en una granjería más, pagándose ciertas cantidades de dinero a cambio de absoluciones ventajosas (Muro Orejón, 1982, p. 56).

En cualquier caso, el proceso de visita reunió una serie de características constantes, más aún si nos referimos a aquella auditoría que empezó en 1664 y que legalmente estuvo abierta hasta finales del siglo XVII, aunque sus efectos fueron nulos. La visita se efectuó en razón de los siguientes parámetros: su principal motivo fue realizar una inspección; los empleados virreinales que estaban siendo visitados nunca eran apartados de sus plazas, salvo casos extraordinarios; no tuvo una aplicación universal y su periodicidad no estaba predefinida; siempre fue una indagación colectiva, nunca indivi- 
dual, por lo que afectaba tanto a las instituciones como a los sujetos que servían en ellas; su alcance geográfico variaba en razón al organismo inspeccionado; y, por último, fue un procedimiento que no contó con límites temporales en cuanto a su finalización, pero sí en las fechas de las materias que iban a ser visitadas (Céspedes del Castillo, 1946, p. 991).

La visita fue una tarea compleja que requirió siempre responsables preparados, capaces y con una trayectoria intachable, pues se buscaba perseguir la corrupción y el resto de desmanes que se cometían en las Indias. Por ello, la elección de los visitadores fue un tema de extrema delicadeza en el Consejo de Indias. La responsabilidad del encargo y las probabilidades de fracasar en el empeño hicieron que esta comisión fuese rechazada por muchos, razón que obligó a los consejeros a optar por individuos advenedizos o que anhelaban la provisión para obtener provechos, ascensos o éxitos de carácter personal. No obstante, aunque ningún visitador pudo aumentar su hacienda sin participar de corruptelas, la consecución de resultados más o menos decentes en la visita sí les facilitó relanzar su carrera; tal fue el caso de Francisco Antonio Manzolo, quien tras inspeccionar las cuentas de la Caja Real de Lima consiguió permanecer en el Perú sirviendo en la misma institución que había auditado.

24 En cualquier caso, los visitadores ostentaban unos poderes tan extendidos como necesarios para su cometido y a la vez se convirtieron en figuras intocables en los distritos donde fueron destinados. Así, con estas capacidades, pudieron rodearse de una suerte de "corte" formada por subalternos y otras personas que, al calor de las posibilidades que el visitador ofrecía, se acercaban con intenciones diversas, desde el ocultamiento de ilegalidades propias a la consecución de 
otros intereses previos a la llegada del visitador. De una $\mathrm{u}$ otra forma, los visitadores estaban rodeados de al menos un secretario, un fiscal, un alguacil mayor, un escribano mayor y un número indeterminado de suboficiales de secretaría, contadores, etc. que pudieron ser extraídos del entorno de destino, llegados desde la península ibérica o acompañantes de un empleo anterior (Céspedes del Castillo, 1946, p. 1006).

Sin embargo, el gran problema de las visitas durante la segunda mitad del XVII no fue solo el crecido poder que adquirían sus encargados, ni tan siquiera lo ineficaz del proceso, sino el gasto que generaban a la Real Hacienda. En este sentido, el conde de Peñaranda, presidente del Consejo de Indias entre 1653 y 1671, manifestó serias dudas sobre la idoneidad de estos procedimientos para controlar a las instituciones y empleados americanos. Para Peñaranda, eran más útiles las indagaciones sobre cada funcionario individual que aplicar las inspecciones a todo el conjunto de un organismo. De esta manera, según el presidente del Consejo de Indias, se reducirían los gastos y la efectividad de la visita crecería; además, sería mucho más difícil que se creasen partidos a favor y en contra de los visitadores, fenómeno que estorbaba la inspección sobremanera y que, valga la redundancia, favoreció corruptelas de tipo nepotista, prevaricador y cohechador entre el encargado de las pesquisas y los sujetos de su entorno (Lohmann Villena, 1946, pp. 26- 27).

La opinión de Peñaranda no logró ocultar que la mayor preocupación en la corte sobre las visitas no residía en su eficacia, sino en sus costes y de ahí que se propusiesen reformas durante casi toda la centuria. Estas inspecciones ocasionaban gastos importantes por lo indefinido de su duración, alargadas siempre lo más posible, puesto que a más meses, más 
tiempo ingresaban los salarios pertinentes y mayores las probabilidades de asentamiento para el auditor en el territorio en cuestión como figura casi inviolable. Así, no resultó extraño que ciertos visitadores acabasen por desvirtuar su comisión alegando lo extenso y farragoso de la tarea, los obstáculos interpuestos por los visitados y las dilaciones causadas, el "factor distancia" que ralentizaba las comunicaciones con el consejo, la escasa valía de las personas subalternas, entre otros motivos recurrentes ante Madrid para incrementar la cuenta de gastos generados por la visita y prolongar, en la medida de lo posible, la estancia en las Indias (Céspedes del Castillo, 1946, p. 1011). Por ello, puede sostenerse que durante la segunda mitad del XVII este método de control e inspección no solo era inválido, sino también desactualizado y un lastre para el fisco regio. El procedimiento no solo no corregía la corrupción, sino que incluso contribuyó a aumentar estas prácticas ilegales. El análisis que voy a realizar sobre la gran visita a la que fue sometida la Audiencia de Lima desde 1664 demuestra que la pervivencia de estos métodos de supervisión fue uno de los grandes fracasos de la administración de la monarquía hispánica en las Indias.

En este marco teórico, puede comprobarse que tanto las visitas como los juicios de residencia fueron procesos de control sobre la administración colonial que arrojaron resultados nefastos para los intereses de la Corona durante la segunda mitad del XVII. Además, fueron adaptados por aquellos que los "sufrían" para mantener redes clientelares, corruptelas e ilegalidades sin freno. Así, la supervisión de la jerarquía gubernativa por parte de la metrópoli, desde el virrey al oficial de la caja real más ínfima, fue diluyéndose sin remedio. El poder coercitivo que se había ejercido en épocas anteriores desde la península ibérica ya apenas sujetaba a unos funcio- 
narios que sabían cómo, cuándo y dónde aprovechar los resortes del Perú y de la legislación indiana para su beneficio propio. Veamos esto con más detalle profundizando en la visita de la que fue objeto el virreinato peruano desde 1664.

\section{La primera pareja de visitadores: Juan Cornejo y Francisco A. Manzolo}

La situación generada en el Perú durante los gobiernos sucesivos del conde de Salvatierra (1648-1655) y, especialmente, del conde de Alba de Liste (1655-1661) crearon una fuerte demanda, casi un clamor, de una inspección a fondo de las instituciones y su personal. El recibo en Madrid de un memorial anónimo, fechado en Lima el 12 de noviembre de 1660 , se convirtió en el detonante para llevar a cabo esta auditoría. El desconocido denunciante escalonaba su texto en veintiocho epígrafes, demostrando basarse en sólidas informaciones, con datos del Tribunal de Cuentas limeño y con cierto apoyo social. Todo ello llevó a pensar que lo advertido desde la Ciudad de los Reyes podía ser incluso más grave, razón por la cual una junta particular del Consejo de Indias se reunió para buscar una solución a estos desmanes denunciados y tratar de reconducir la situación del virreinato. Así, se acordó enviar a un juez visitador para inspeccionar todas las instituciones radicadas en la jurisdicción de la Audiencia de Lima y cortar de raíz las corruptelas e ilegalidades detectadas. No obstante, los consejeros intuyeron que esta labor iba a ser ardua. Por este motivo, en la corte se optó que la visita no fuese conminada a un solo individuo, sino que las pesquisas se dividiesen en dos bloques: por un lado, la Audiencia, el Juzgado de Bienes de Difuntos, el Tribunal de la Santa Cruzada, el Consulado de Lima y el Correo Mayor de Indias; y por otro, el Tribunal 
de Cuentas y la Caja Real limeña (Lohmann Villena, 1946, pp. 72-73).

El Consejo de Indias pretendía con esta partición que la visita no acabase en fracaso, como otras que habían tenido lugar años atrás y por ello se detuvo en la elección de los inspectores. Así, para el primero de los bloques el designado acabó siendo Juan Cornejo, aunque no fue el escogido en primera instancia. Los consejeros llegaron a consultar al rey sobre la idoneidad de este sujeto, que terminó por ser provisto gracias a un par de motivos: el rechazo de Francisco Henríquez de Ablitas al encargo y el hecho de que Cornejo ya se encontrase en las Indias inspeccionando la Audiencia de Santa Fe. En el Consejo, entendieron que estas pesquisas estaban en las últimas fases, por lo que el traslado de Cornejo de Bogotá a Lima no habría de demorarse en demasía y así podría empezar a trabajar sin grandes dilaciones ${ }^{4}$.

Para las tareas de inspección en los organismos hacendísticos, los consejeros consultaron con Felipe IV un nombre: Francisco Antonio Manzolo. Aprobado sin trabas, a este visitador se le asignó un sueldo de 6.000 pesos anuales, pero no consignado a una Caja Real, sino para extraer de los alcances que tomase ${ }^{5}$. Este modo de retribución, diferenciado del directo que iba a recibir Cornejo, hacía presagiar una convivencia 28 complicada entre ambos inspectores $y$, por tanto, una dificul-

4 Consulta del Consejo de Indias al Rey sobre el nombramiento como visitador de Lima de Juan Cornejo. Archivo General de Indias (AGI), Lima, 280. Madrid, 20 de septiembre de 1662.

5 Consulta del Consejo de Indias al Rey sobre el nombramiento como visitador de Lima de Francisco Antonio Manzolo. AGI, Lima, 280. Madrid, 27 de septiembre de 1662 . 
tad adicional en la visita. Mientras uno podía engrosar deudas contra la Real Hacienda para aumentar su retribución, el otro apenas podría rentabilizar legalmente su estancia en el Perú. La visita había fracasado antes de empezar.

El proceso de inspección y control sobre la administración peruana no arrancó de forma coordinada. Si bien los visitadores llegaron a Lima desde lugares diferentes, su puesta en marcha no fue coordinada. Así, el 16 de abril de 1663, el virrey conde de Santisteban notificó a la corte el recibo de los reales despachos que ordenaban la visita a la Audiencia, Tribunal de Cuentas, cajas reales, etc., por parte de Cornejo y Manzolo, pero también hizo saber que no se tenían nuevas de ambos inspectores ${ }^{6}$. Casi tres meses más tarde, Francisco Antonio Manzolo tomó posesión de su plaza ${ }^{7}$. De inmediato, sin esperar a Cornejo, el inspector hacendístico se puso manos a la obra, concentrándose en la auditoría de los libros contables depositados en el Tribunal de Cuentas. Las ansias laborales de Manzolo originaron el primero de los problemas de esta visita. Según el visitador, apenas tenía espacio para trabajar sobre estas contabilidades, por lo que necesitaba que la Sala del Crimen de la Audiencia fuese desalojada. Esto ocasionó una protesta enérgica de los alcaldes ante el virrey, pues entendían que era un espacio reservado para sus obligaciones y bien comunicado con las salas civiles de los oidores. Santisteban, ante el dilema, optó por esperar a que el Consejo de Indias asignase las habita-

6 Carta del conde de Santisteban al Rey. AGI, Lima, 64. Lima, 16 de abril de 1663.

7 Carta del conde de Santisteban al Rey. AGI, Lima, 64. Lima, 11 de julio de 1663. 
ciones audienciales ${ }^{8}$. En cualquier caso, los primeros pasos de Manzolo no fueron nada acertados: se ganó la enemistad de los alcaldes del crimen y puso en un aprieto al virrey, lo cual favoreció su predisposición amistosa hacia el visitador que estaba por llegar.

Catorce meses después de la llegada de Manzolo, el 8 de septiembre de 1664 hizo su entrada en Lima el otro juez visitador: Juan Cornejo. Rechazando ser el protagonista de una entrada solemne al estilo propio de los virreyes, el inspector fue recibido por el conde de Santisteban en el palacio y allí no tardó mucho en ganarse su simpatía y favor. Cornejo fue aupado por el alter ego por encima de sus competencias y así fue invitado a participar en las sesiones del Real Acuerdo. Pero lo que más malestar causó fue la influencia ejercida por el visitador sobre el virrey, pues llegaron a publicarse dictados de Santisteban que se debían solo a la opinión del inspector. Por ello, en la Audiencia de Lima comenzó a relucir cierto malestar contra el visitador. El decano de la chancillería, Francisco Sarmiento de Mendoza, y el protector de los naturales, Diego de León Pinelo, no tardaron en rebelarse frente al encargado de realizar las pesquisas en su institución y de ahí que decidiesen formar un partido para entorpecer su tarea (Lohmann Villena, 1946, p. 75). Si bien es cierto que Cornejo solo mostraba interés por alinearse con el virrey, inclu30 so puede decirse que controlarlo (Jiménez Jiménez, 2015b, p. 91), la postura tomada por algunos togados tampoco fue muy adecuada: el visitador estaba en Lima precisamente para evitar que en la Audiencia se cometiesen o amparasen de-

8 Carta del conde de Santisteban al Rey. AGI, Lima, 65. Lima, 29 de julio de 1663. 
litos, ilegalidades y corruptelas, pero la opción elegida por Sarmiento de Mendoza y León Pinelo no pudo ser calificada de otra forma que de prevaricadora.

A finales de 1664 parecía que los escándalos, abusos y corrupciones no iban a acabar por el simple hecho de que los visitadores ya se hubiesen puesto a trabajar en Lima. La oposición de los magistrados de la Audiencia no fue el único escollo de los auditores, pues el descenso de los ingresos fiscales hizo que el visitador Manzolo se centrase en detectar primero qué pasaba con la recaudación de tributos. Además, Cornejo sumó a su lista de contrarios a los oficiales reales que debía inspeccionar su compañero. Cornejo decidió deponer a todo aquel empleado de la Caja Real limeña que había adquirido el puesto en almoneda, pues interpretó que eran los causantes de buena parte de los fraudes denunciados (Glave Testino, 1989, p. 204). Así, la intromisión de Cornejo en las esferas asignadas a Manzolo fue la ignición definitiva para su enfrentamiento, lo que, para desgracia de todos, dio al traste con la visita.

Los primeros choques entre Cornejo y Manzolo se notificaron en noviembre de 1664. El virrey Santisteban hubo de comunicar a la corte que su protegido, el primero de los visitadores, estaba sufriendo una serie de desafectos por parte del inspector hacendístico. Pero Manzolo no mantuvo una actitud pasiva ante los ataques y las intromisiones realizadas por Cornejo. El agraviado visitador defendió su parcela y buscó obtener las mismas ventajas en las indagaciones que su colega. Así, decidió asistir a todas las juntas de hacienda, aun sin invitación, y con participación de voz y voto, e incluso presentó a estas reuniones informes que solo debía haber visto 
el virrey antes de su envío a España9. Pero ni las denuncias al respecto realizadas por Santisteban, las cuales difieren mucho de lo realizado por su protegido Cornejo, disuadieron al visitador de continuar con estas prácticas poco ortodoxas. Así, el 13 de noviembre de 1664 se produjo una nueva sesión de la junta hacendística con la presencia de Manzolo. El enfrentamiento abierto con el virrey apenas tuvo consecuencias, pues la atención rápidamente pasó al otro auditor, como así relataron los oficiales reales Pedro Quesada Malavet y Francisco Flores ${ }^{10}$.

En diciembre de 1664, Cornejo aprovechó ciertas circunstancias a favor de sus intereses y para la construcción de una red clientelar. Después de unas semanas como visitador, se demostró que sus motivaciones en el Perú no coincidían con las instrucciones del Consejo de Indias. El inspector comunicó a la corte que, por haber tenido noticia del fallecimiento de Antonio de Miranda, el provisto como alguacil de las comisiones de la visita, había decidido nombrar un sustituto a su conveniencia, aun sin potestad para ello. El elegido fue Sebastián Velázquez Maldonado, sujeto con dotes para el oficio y que además presentaba la "ventaja" de ser, en palabras de Cornejo, de "mi casa y de mi satisfacción" ${ }^{11}$. Sin duda, la conveniencia de esta provisión ilegal y nepotista ${ }^{12}$ era enorme

9 Carta del conde de Santisteban al Rey. AGI, Lima, 65. Lima, 3 de noviembre de 1664 .

10 Carta de los oficiales reales Pedro Quesada Malavet y Francisco Flores al Rey. AGI, Lima, 65. Lima, 15 de noviembre de 1664.

11 Carta del visitador Juan Cornejo al Rey. AGI, Lima, 280. Lima, 9 de diciembre de 1664.

12 Es importante tener siempre en cuenta cómo los "entramados nepóticos de las instituciones coloniales", junto con la ductilidad del Derecho Indiano y la corrupción sin castigar, fueron claves para el asentamiento de 
para el inspector, pero no hubo persona o institución que se atreviese a contradecirla, máxime cuando el propio virrey ejercía como su protector.

Probablemente, el aumento de apoyos clientelares fue lo que hizo que Cornejo elevase su nivel de críticas sobre su compañero Manzolo. Así, el visitador dio buena cuenta de las acciones familiares y los contactos que estaba aunando el inspector hacendístico, a pesar de que ambos tenían prohibido enlazar con personas de la jurisdicción. Esto, según Cornejo, pareció importar poco a Manzolo, pues tomó por esposa a Catalina Bravo, viuda del oidor de la Audiencia de Panamá Francisco Dávila Muñoz e hija del difunto contador del Tribunal de Cuentas Fernando Bravo de Lagunas; es decir, una mujer con parentela política de primer orden e inserta en la institución que su nuevo esposo estaba auditando. Para Cornejo, que actuó de forma similar, este no fue el desaire más grave cometido por su compañero. El visitador consideró más lesivo el que Manzolo se mostrase contrario al partidismo del virrey Santisteban, que accediese a la Junta de Hacienda sin facultad o ignorase las advertencias del Real Acuerdo, que no contase con él para coordinar las inspecciones, que retirase de empleo y sueldo a varios contadores sin potestad para tal, etc. Pero lo que más dolió a Cornejo fue que, tras cierta normalización de las relaciones con Manzolo, se le obligó a acompañarlo desde su residencia hasta el palacio virreinal en una suerte de procesión expiatoria ${ }^{13}$.

la clase criolla en las instituciones de gobierno (Smietnianksy, 2007, p. $80)$.

13 Carta del visitador Juan Cornejo al Rey. AGI, Lima, 64. Lima, 9 de diciembre de 1664. 
Aunque Cornejo no se aplicó en la visita de manera tan rápida y eficaz como había demostrado Manzolo, sí que se dedicó a entablar unas relaciones similares a las de su compañero; a pesar de que, como han leído, él fue su delator. Así, Cornejo, quien ya estaba casado cuando pasó al Perú, mantuvo lazos casi parentales basados en la pertenencia a una especie de corte personal. Tras la provisión de Sebastián Velázquez Maldonado, Cornejo necesitó de otros resortes en las instituciones virreinales. Uno de los elegidos y a la postre su principal cliente y mano derecha fue el contador Sebastián de Navarrete. En febrero de 1665, hizo saber a Madrid que los múltiples fraudes que se cometían en el puerto del Callao o los elevadísimos gastos del presidio bajo la responsabilidad de Navarrete no podrían ser excusa para prescindir de sus servicios en la visita. De esta forma, comunicó su decisión, sin consulta alguna, de nombrar a Navarrete como superintendente de la rada chalaca bajo su supervisión ${ }^{14}$.

Un año más tarde de las primeras discordancias entre los visitadores, causa importante del fracaso de su comisión, volvieron a repetirse las tensiones. En esta ocasión, fue Manzolo quien señaló los enfrentamientos que había mantenido con Cornejo, poniendo especial atención en las advertencias fiscales que le realizó y fueron ignoradas. El inspector hacendís-

34 tico había seńalado al otro visitador el cuidado extremo con que tenían que tratar los negocios del arrendamiento de los tributos de la alcabala, la avería y el almojarifazgo, asientos de suma gravedad (Jiménez Jiménez, 2016, p. 45). Manzolo

14 Carta del visitador Juan Cornejo al Rey. AGI, Lima, 280. Lima, 4 de febrero de 1665 . 
no fue partidario de entregar el cobro y administración de estos impuestos al Consulado de Lima, pero, a pesar de sus argumentos, Cornejo se mostró contrario y favorable a entregar los gravámenes a los cargadores. Además, la opinión de Cornejo era coincidente con la del virrey Santisteban, quien estaba ansioso por incrementar las remesas con destino a Sevilla ${ }^{15}$.

Aunque no cabe duda de que las cuestiones fiscales tuvieron un peso capital en la administración colonial y que la delicadeza primaba a la hora de visitar a sus organismos, para Manzolo hubo un reproche más importante que lanzar contra Cornejo. El primero comunicó a la corte las graves discrepancias mantenidas con su colega en torno a las modificaciones tributarias en el distrito de San Antonio de Esquilache. Manzolo recomendó que no se bajasen los quintos a los mineros de la jurisdicción, pero Cornejo presionó al Real Acuerdo para cambiar el impuesto al sexto de las barras fundidas ${ }^{16}$. El verdadero problema no estaba en la reducción de la Caja Real, sino en que con esta medida se favorecía a los revoltosos hermanos Salcedo, próximos a la clientela de Cornejo y a su industria argentífera. Así, cuando estallaron las alteraciones de Laicacota, las primeras noticias no llegaron al virrey ni a la Audiencia, sino al visitador que tanto apoyaba al bando andaluz de este levantamiento. El primero en escribir a Cornejo fue Gaspar de la Serna Salazar, quien se ofreció como brazo ejecutor en la región puneña, pues según manifestó, los hechos estaban "siendo muy dañinos para sus

15 Carta del visitador Francisco Antonio Manzolo al Rey. AGI, Lima, 280. Lima, 20 de noviembre de 1665.

16 Carta del visitador Francisco Antonio Manzolo al Rey. AGI, Lima, 280. Lima, 20 de noviembre de 1665. 
intereses”. Además, De la Serna se adelantó a la respuesta del visitador y reveló parte de su estructura clientelar, al declarar que ya se había puesto al servicio de Francisco Romero, "por saber es del agrado de v.m." ${ }^{17}$.

Cornejo volcó más esfuerzos en asentarse en la jurisdicción de Lima, que en inspeccionar las instituciones que se le habían encomendado. Por esta dejación de obligaciones, los escasos resultados remitidos a Madrid y lo poco conveniente que fue mantener a dos inspectores enfrentados, el Consejo de Indias decidió, mediante una real cédula datada el 3 de marzo de 1666, que Juan Cornejo regresase inmediatamente a España. Una decisión que no implicó la suspensión de la visita. Cornejo había recibido orden de partir cuanto antes y llevar consigo toda la documentación generada en sus indagaciones para su examen en el consejo. Sin embargo, desde la emisión de la real cédula hasta su recibo en Lima, el visitador continuó ejerciendo casi sin límites. La llegada a la capital virreinal de esta disposición el 10 de septiembre de 1666 cambió esta situación, pues desde entonces los enemigos acérrimos de Cornejo, los miembros de la audiencia -que a la postre ejercía como gobernadora del virreinato por la muerte del virrey Santisteban-, se encargaron de torpedear cuantas acciones llevase a cabo o tan siquiera intentase ${ }^{18}$.

36 Depuesto Cornejo, no tardaron en producirse denuncias sobre su actuación, aunque hubo algunas realizadas antes de haber sido apartado. Pedro Santiago Concha, proveedor general del

17 Carta de Gaspar de la Serna Salazar al visitador Juan Cornejo. AGI, Lima, 280. Puno, 9 de enero de 1666.

18 Carta de los oidores de la Audiencia de Lima al Rey. AGI, Lima, 66. Lima, 15 de junio de 1666. 
Callao, acusó al visitador de las siguientes corruptelas e ilegalidades: que el hijo de Cornejo servía como capitán de infantería a pesar de tener solo doce años y que otro sobrino suyo estaba empleado como alférez, aunque este sí era mayor de edad; que el corregimiento de Carabaya se le había dado a un criado de Cornejo por su influencia sobre el conde de Santisteban; y que había reunido a testigos falsos, ayudado por Sebastián de Navarrete, para difamar su labor al frente de la proveeduría chalaca ${ }^{19}$. Por ello, fueron puestas en tela de juicio todas las acciones realizadas por Cornejo en torno a la Real Hacienda -que, recordemos, no eran de su competencia- y la administración de las armas peruanas, pues se sospechaba que el visitador y su cliente Navarrete buscaban beneficios personales. Además, al oidor Lope Antonio de Munibe se le encargó que indagase si los cargos que Cornejo había imputado al oficial real Francisco de Colmenares eran ciertos o falsos y si estos, como se temía, favorecían a Navarrete ${ }^{20}$. Nepotismo, prevaricación y cohecho protagonizados por un individuo que había sido provisto en el virreinato para acabar con las corruptelas en curso, no para participar de las mismas.

La vuelta de Juan Cornejo a la península ibérica no fue ni mucho menos fácil. La Audiencia le acusó de no realizar la copia de los autos sacados para su conservación bajo llave en sus instalaciones por motivos de seguridad, pero Cornejo se negó tajantemente a ello. La Audiencia emitió dos reales cédulas dirigidas al visitador conminándolo a que hiciese sendas copias y las depositase "en arca segura", pero él solo acep-

19 Carta de Pedro Santiago Concha al Rey. AGI, Lima, 170. Lima, 18 de junio de 1666.

20 Orden de la Audiencia de Lima al oidor Lope Antonio de Munibe. AGI, Lima, 72. S.l., s.f. 
tó que se hiciese una reproducción si esta iba a ser guardada en el palacio virreinal bajo tres llaves: una para el arzobispo Pedro de Villagómez, otra para el inquisidor decano y una última para el provincial de los jesuitas. Cornejo se mostraba reservado y temeroso de los togados, quienes se estaban moviendo bajo un simple "apetito de venganza"21. A la postre, Cornejo hubo de confeccionar aquella copia de sus escasos autos y la Audiencia tuvo que informar sobre lo ejecutado por el visitador, aunque en ambas obligaciones el desquite no pudo, ni quiso, esquivarse.

El resumen, casi una crónica, que la Chancillería de los Reyes realizó sobre la actuación de Juan Cornejo como visitador en Perú no tiene desperdicio en cuanto, entre otras cosas, al fracaso de este medio como controlador de la administración colonial. El informe comienza con una protesta sobre la altivez con la que había procedido Cornejo, pero no achacaba esta conducta al propio carácter del sujeto, sino que los magistrados consideraban que el causante de esta era el virrey conde de Santisteban por su protección. Sin embargo, en opinión de la Audiencia no todos los desastres de la visita eran atribuibles a terceras personas, muchos solo eran responsabilidad del inspector y así lo relatan. Los magistrados acusaron a Cornejo de enviar a todos los rincones del virreinato una serie de avisos en los que anunciaba su poder sobre cualquier cuestión de justicia

38 y gobierno tras la muerte de Santisteban, facultades que no tuvo asignadas en ningún momento. Cornejo intervino en el Real Acuerdo, vetando todas las decisiones que se tomaban contrarias a su parecer, con el pretexto de la visita; incluso ac-

21 Carta de los oidores de la Audiencia de Lima al Rey. AGI, Lima, 66. Lima, 3 de diciembre de 1666. 
tuó en procesos judiciales como si fuese juez. El visitador se opuso a los fiscales en ciertos pleitos para favorecer a particulares y, alegando la inspección, retuvo y adjudicó otros juicios para retrasarlos en favor de una parte y obtener algún beneficio cohechador, sobre todo en aquellos en los que se dirimían fuertes sumas de dinero. Cornejo retuvo cuantas ejecutorias del Consejo de Indias no le parecieron convenientes e incluso animó a Gaspar de Salcedo a comprar el nombramiento como corregidor de Laicacota, gracias al cual se embolsó, por cuenta del minero andaluz, unos 50.000 pesos al contado y otros 10.000 en un segundo plazo. La Audiencia también señaló que Cornejo había inspeccionado los fraudes que se cometían en el Callao hasta encontrarse con miembros de su clientela; razón por la cual detuvo las pesquisas, pues como expresaron los togados "no podemos asegurar el motivo, solo es cierto que los culpados son poderosos y ricos”. Por último, los magistrados denunciaron que el visitador agasajó, "como adeudo de su mujer", a Antonio Núñez de Monroy con dos corregimientos y otras plazas para aumento de su hacienda, lo cual explicaba el pleito que Cornejo puso para reclamar su herencia tras su fallecimiento $^{22}$. La Audiencia, enemistada con el visitador, reveló un buen muestrario de razones que explican el fracaso de esta herramienta de control sobre las instituciones indianas.

La visita nunca pudo funcionar si su encargado actuaba como describieron los magistrados, pero aun así la retirada de Cornejo no supuso el fin de estas pesquisas, aunque sí la pérdida del impulso inicial de 1664. Tras esta marcha, Francisco Antonio Manzolo continuó sus indagaciones en el Tribunal

22 Carta de los oidores de la Audiencia de Lima al Rey. AGI, Lima, 102. Lima, 6 de diciembre de 1666. 
de Cuentas y en la Caja Real de Lima, pero su labor apenas produjo resultados reseñables. Este visitador se limitó a pulir y actualizar los métodos contables y auditores del Tribunal y prestó especial atención al cobro de alcances, ya que de ahí extraía sus retribuciones. Por ello, Manzolo fue adaptándose a la propia plantilla de las instituciones que estaba inspeccionando, hasta el punto en que no se distinguió al visitador de otro oficial real o contador, pues trabajaba codo con codo con todos ellos (Andrien, 2011, p. 221). Sin embargo, su permanencia en Lima y esta forma de proceder no fueron del agrado de muchos, especialmente de quienes deseaban una visita más protocolaria y que limpiara a fondo la administración virreinal. Así, en 1668 se remitió a Madrid un memorial anónimo recriminando al virrey conde de Lemos que no hiciese nada por reanudar con fuerza la visita, pues era necesaria según el parecer de este desconocido escritor; además, para apoyar esta urgencia el desconocido autor desgranó los parentescos y los intereses existentes entre los miembros de la Audiencia limeña ${ }^{23}$. De esta forma, se buscaba reiniciar una administración que sus coetáneos tachaban de corrupta.

Casi al mismo tiempo que se redactó aquel memorial anónimo, en 1668 el Consejo de Indias notificó a Manzolo las dudas existentes sobre su proceder en la visita, ya que apenas tenían noticias de avances o conclusiones más o menos só-

40 lidas. Tras cinco años de visita, el Consejo mostró reparos a su permanencia en Perú, pues sospechaban que el empeño de Manzolo por continuar en Lima no estaba justificado con su trabajo en las cajas reales. Es decir, la visita fiscal tampoco ha-

23 Memorial anónimo en favor de visitar la Audiencia de Lima. AGI, Lima, 70. S.l., 14 de agosto de 1668. 
bía funcionado. Manzolo achacó el retraso a la delicadeza de la tarea, pero otras voces apuntaban a su conversión en "árbitro y dueño" del Tribunal de Cuentas al obligar que todos los libros pasasen por sus manos. Una manera de proceder a todas luces equivocada, dado el inmenso volumen de contabilidades. Así, por los pocos avances logrados por Manzolo, el conde de Lemos tuvo a bien tomarse facultades que no tenía conferidas -la visita era competencia exclusiva del Consejo de Indias- y reasignó al visitador a la Caja Real de Potosí, pues los rezagos y el desorden en la misma también requerían una inspección urgente (Lohmann Villena, 1946, p. 304).

Sin embargo, la dedicación de Manzolo al Tribunal de Cuentas no provocó el abandono de la investigación a otras instituciones. Pero como un solo hombre no podía llevar las contabilidades de la institución auditora, el visitador se rodeó de una serie de oficiales a sus órdenes. De esta manera, Manzolo pudo centrarse en los rezagos de las cajas reales y los débitos de los corregidores, pues en estos casos los beneficios personales eran mayores. Al destaparse esta situación, el virrey Lemos encargó una investigación a fondo sobre el proceder de Manzolo. Las pesquisas revelaron que el visitador había extraído de la Caja Real de Lima en siete años, desde 1663 hasta 1670 , un total de 19.468 pesos y 4 reales en concepto de salario para sus oficiales. Cantidades elevadas y sin correspondencia con los sueldos usuales para estos contables de segunda categoría. Conocido esto por el virrey, se ordenó el desmantelamiento de la red clientelar de Manzolo y lo acusaron de actuar en detrimento de la Real Hacienda al no presentar apenas resultados de su investigación ${ }^{24}$.

24 Carta del conde de Lemos al Rey. AGI, Lima, 70. Lima, 4 de febrero de 1670. 
Ante esta situación, Manzolo se vio en una suerte de destierro por su "distracción" como visitador. Como se ha apuntado, el virrey Lemos decidió enviar a Manzolo a Potosí con el pretexto de inspeccionar aquella Caja Real, pero como este tenía capacidad para quedarse en cualquier otra caja con objeto de auditarla, se le prohibió expresamente detenerse hasta llegar a la ciudad minera. Esta orden fue aceptada a regañadientes por Manzolo, que sabía que tarde o temprano iba a regresar a Lima, pero aun así buscó beneficiarse solicitando una 'ayuda de costa’ de 1.000 de pesos. El virrey Lemos le concedió esta subvención, pero en un nuevo error, muy similar al cometido por el Consejo de Indias en 1662 en sus instrucciones, se le dotaron estos pesos extrayéndolos de las condenaciones y resultas que sacase del Erario Regio en la caja potosina ${ }^{25}$. Así, el visitador indagó sobre el máximo posible de deudas para incrementar su propia hacienda, algo para lo que estaba facultado.

En cualquier caso, fue patente que la segunda sección de la visita había fracasado con igual estrépito. No obstante, Manzolo, al contrario que Cornejo, no solo no regresó a España, sino que se mantuvo en el virreinato del Perú y al volver a la Ciudad de los Reyes lo hizo en calidad de propietario de una plaza de contador del Tribunal de Cuentas, una de las principales instituciones que debió haber auditado a fondo. Una paradoja significativa de lo nefasto que fue durante la 42 segunda mitad del siglo XVII abrir unos procesos de inspección, que apenas habían sido actualizados desde la centuria anterior y que estaban siendo aplicados en un contexto colonial más evolucionado.

25 Carta del conde de Lemos al Rey. AGI, Lima, 70. Lima, 11 de marzo de 1670. 


\section{La yerma sucesión de inspectores}

Apartados definitivamente los visitadores Cornejo y Manzolo en 1670, las instituciones coloniales siguieron precisando una auditoría de primera magnitud. Las demandas para tal efecto se venían realizando desde 1668 , pero los costes ocasionados por el intento anterior alejaban al Consejo de Indias de dar una respuesta afirmativa a esas peticiones. La solución adoptada fue continuar las pesquisas sobre la administración peruana encargándoselas a alguien que ya formase parte de la estructura y que a su vez fuese un sujeto de intachable reputación y admirada conducta. Pero figuras que respondiesen a estas características no abundaban, como lo demostraban las acusaciones cruzadas que se producían entre magistrados y visitadores. No obstante, la llegada del conde de Lemos a Lima propició el ascenso al primer escalafón político de un individuo respetado e "incorruptible": Álvaro de Ybarra (Jiménez Jiménez, 2013, pp. 313-325).

Así, en 1670 fue renovada la visita nombrándose a Ybarra, antiguo inquisidor y para entonces oidor de la Audiencia limeña, como su único encargado. Igual que fue acotada la tarea en 1662, esta vez se decidió que la inspección no tuviese un carácter general, sino que se centrase exclusivamente en la Audiencia de Lima y específicamente en aquellos magistrados que habían sido objeto de las críticas más duras por parte de Cornejo (Basadre Grohmann, 1939, p. 11). Un encargo cuanto menos delicado, pero del que no rehuyó el nuevo visitador; quien sin duda manejaba, con apoyo de su asentada red clientelar y del virrey, las salas chancillerescas.

Apenas un año bastó a Ybarra para comenzar a remitir informaciones al Consejo de Indias sobre los numerosos desma- 
nes que estaba conociendo y destapando. En marzo de 1671, escribió a la península haciendo saber que había empezado a investigar ciertos fraudes que se cometían en torno al situado de Chile, pero que como no tenía acceso directo a la documentación conservada en Santiago tuvo que nombrar, mediante comisión directa, a Gaspar de Cuba y Arce, oidor en aquella jurisdicción, como juez de apoyo en estas pesquisas. Sin embargo, los resultados no fluyeron tal y como esperó Ybarra, pues su colega chileno tras aceptar el trabajo lo rechazó aludiendo la imposibilidad de extraer fondos de la Real Hacienda de Chile con los que pagar su tarea extraordinaria. La negativa de Cuba y Arce para proceder con las pesquisas encomendadas desde Lima al menos dejó la confirmación de que las sospechas de desfalco y cohecho fueron ciertas. El oidor, además de lo relacionado con el salario, rehusó participar en la visita porque el veedor y los oficiales reales de la Caja de Concepción ya habían fallecido y por mucho que se hallasen cargos contra ellos, no habría de dónde satisfacer las penas y condenaciones, ya que no habían legado bienes que pudiesen ser embargados. A pesar de que nunca se llevaría a cabo una investigación concienzuda en aquel distrito por la citada falta de fondos, Ybarra ordenó que se ejecutasen cuantas indagaciones fuesen necesarias para, al menos, saber hasta dónde había llegado el daño al fisco real ${ }^{26}$.

44 Ni que decir tiene que, aunque la comisión visitadora de Ybarra estaba limitada a la Audiencia limeña, pronto sus indagaciones abarcaron competencias mayores hasta incluir las instituciones hacendísticas. La intromisión del visitador en la

26 Carta de Álvaro de Ybarra al Rey. AGI, Lima, 280. Lima, 29 de marzo de 1671. 
Caja Real de Lima y en el Tribunal de Cuentas no fue bien recibida por sus plantillas, razón por la cual sus pesquisas fueron torpedeadas. Así, el contador Sebastián de Navarrete -antiguo colaborador de Cornejo- para defenderse de las acusaciones de corrupción, entabló cuantas recusaciones estimó oportunas a fin de impedir que Ybarra entrase bien a fondo en la Caja. Estas trabas fueron conocidas por el virrey conde de Castellar, pues a figura tan economizadora y atenta a los intereses de la Real Hacienda interesó mucho la visita sobre los organismos fiscales.

Ybarra apenas había podido realizar avances en estas auditorías, demostrándose nuevamente lo fracasado del modelo visitador en la segunda mitad del siglo XVII, pero desde el palacio virreinal se consideró necesario que estas investigaciones se llevasen a cabo con una seriedad extrema, pues era la única vía para conocer el estado real del fisco y, sobre todo, las grietas por las que se perdían sus fondos. De esta manera, apenas un mes después del fallecimiento de Ybarra en enero de 1675, el virrey Castellar notificó a la corte los impedimentos que había sufrido el difunto y lo imperioso que resultaba continuar el proceso de visita. Castellar rescató la decisión del Consejo de 1662 y propuso que se designasen dos jueces, uno para la Audiencia de Lima y otro en exclusiva para la Caja Real y el Tribunal de Cuentas. El virrey apoyó comisionar -a la postre serían los elegidos- al oidor Agustín Mauricio de Villavicencio y al contador del Tribunal Juan de Saiçeta y Cucho. Estos individuos no fueron elegidos al azar por sus dotes o por cuestiones nepotista-clientelares, sino porque en palabras del virrey: "aunque a cualquiera de los ministros togados de esta Audiencia se pudiera encargar esta comisión, no hallo ninguno sin recelo de que por sí sus mujeres, parientes o amigos estén sin alguna dependencia en 
la Caja u con los ministros de ella por los muchos años que ha que asisten en esta ciudad" 27 . La visita era tan necesaria como imposible de ser ejecutada en las condiciones óptimas y de aislamiento que requería.

Las percepciones sobre la inspección no eran negativas, ni en Madrid ni en Lima, por lo que tras la muerte de Ybarra la visita iniciada en 1664 se prolongó en una tercera etapa. Así, los propuestos por Castellar, Villavicencio y Saiçeta y Cucho, recibieron su real cédula de nombramiento en 1677. Estos, como apuntó el virrey en su recomendación, eran solo la designación menos mala. Como miembros de la administración peruana, uno oidor y el otro contador por vía venal del Tribunal de Cuentas desde 1652, mantuvieron implicaciones, lazos e intereses en las propias instituciones que debían investigar y con las personas que debían depurar. Quizás por ello, el Consejo de Indias quiso darle un nuevo rumbo a la visita. Si a Ybarra le dieron instrucciones precisas para que centrase su trabajo en la Audiencia, al nuevo binomio de visitadores se les ordenó volcar sus esfuerzos en los organismos hacendísticos, en especial en la Caja Real de Lima (Andrien, 2011, p. 235); no obstante, esta fue la institución menos visitada desde que comenzó el proceso, aunque por ella pasasen buena parte de los caudales del fisco peruano.

46 La elección de otra pareja para proseguir la visita desembocó en un desastre similar al producido por Cornejo y Manzolo, pues Villavicencio y Saiçeta y Cucho tampoco coordinaron lo más mínimo en sus inspecciones. Es más, el oidor ni siquiera prestó atención al trabajo sobre la Caja Real limeña, lo

27 Carta del conde de Castellar al Rey. AGI, Escribanía de Cámara, 536 A. Lima, 15 de febrero de 1675. 
que causó severas y continuas quejas por parte del contador. En cualquier caso, estos problemas de "compatibilidad" acabaron por resolverse de una forma trágica. El fallecimiento de Agustín Mauricio de Villavicencio en 1680, apenas tres años después de comenzar la visita, dejó el proceso en una situación de incertidumbre, pero por su continuidad, no por sus frutos. No se había previsto que Saiçeta y Cucho pudiera continuar las pesquisas en solitario o presentar los resultados ante el Consejo de Indias y la Audiencia de Lima, por lo que se generó cierta inestabilidad. El virrey-arzobispo Melchor de Liñán y Cisneros, a la espera de órdenes desde la península ibérica, optó por asegurar cuánto se llevaba avanzado en la visita y para ello expidió sendos autos en los que mandaba recoger cuanta documentación hubiesen generado los dos visitadores y depositarla en un arca de tres llaves hasta el nombramiento de un sustituto para el togado (Hanke y Rodríguez, 1980, p. 232).

La llegada del nuevo virrey, el duque de la Palata, no produjo cambio alguno en la visita. Es más, el recién llegado alter ego se encontró con el problema de proponer ante el Consejo de Indias a un sustituto para Villavicencio que dirigiese el proceso y acompañase a Saiçeta y Cucho. Pero la decisión final no estuvo en manos de Palata, pues apenas conocía a los magistrados activos en el Perú. Así, en 1681 el Consejo designó al fiscal Juan de Peńalosa como nuevo visitador. El togado no recibió el nombramiento con especial ilusión, por lo que se negaba indirectamente a asumir la tarea. Peńalosa no encontraba ninguna razón para rehusar la comisión, pero conocía perfectamente la trayectoria que habían recorrido los visitadores durante el siglo XVII y no pensaba hipotecar su carrera político-judicial investigando a sus propios compañeros o a la Caja Real de Lima. En palabras del doctor Andrien, Peña- 
losa "temía el tradicional rencor que el establishment político limeño mostrase para con la visita general" (2011, p. 238).

Sin embargo, las órdenes reales fueron acatadas por encima de los deseos personales y Peñalosa se sumó a la visita que continuaba realizando Saiçeta y Cucho. El duque de la Palata dio buena cuenta de ello en 1685 -es decir, con una distancia de cuatro años-, pero no lo hizo con el sentido positivo que se esperaba de un proceso que ya había superado los veinte años y hasta cinco personas responsables. El virrey manifestó al Consejo que los esfuerzos de Peñalosa y Saiçeta y Cucho eran muy considerables, pero que no esperasen ningún tipo de resultado en sus pesquisas a la Caja Real de Lima, ya que ambos visitadores estaban "tan encontrados entre sí, por los dictámenes o por la condición" 28 . Una vez más, la falta de sintonía entre las personas encargadas de las inspecciones, además de las trabas y otros obstáculos, daba al traste con todo el proceso. Pareció ser que, al igual que ocurrió con la visita en sí, las autoridades no aprendieron a solucionar el problema de la elección de los visitadores para dotar de eficacia a este sistema de control.

La muerte del contador Juan de Saiçeta y Cucho, seguida del caos generado por el terremoto de octubre de 1687 y la sustitución del duque de la Palata como virrey, no fueron óbice 48 para que la visita -denominada "general", pero en la realidad muy limitada a uno u otro organismo- fuese interrumpida o dada por finalizada, con independencia de los resultados obtenidos. Sin embargo, el impulso y la renovación pretendida desde 1664, 1670 o 1675 perdió para siempre toda su

28 Carta del duque de la Palata al Rey. AGI, Lima, 85. Lima, 24 de marzo de 1685. 
fuerza, por lo que, aunque se prosiguieron las pesquisas, estas fueron mucho menos importantes, con limitado alcance y de poca profundidad. La llegada al Perú como virrey del conde de la Monclova, persona de formación militar y de intereses puramente conservadores, terminó por desacelerar la visita. Monclova optó por cercenar cualquier discusión sobre su autoridad, eliminar las disputas en el seno de la Audiencia y moderar cuantas reformas fuesen propuestas por los arbitristas, dejando de lado la farragosa implicación que suponía limpiar las instituciones empleando las herramientas visitadoras (Andrien, 2011, p. 242).

Podría decirse que a finales del siglo XVII las visitas como instrumento de control habían muerto, pues ni los más interesados en que se llevasen a cabo -los virreyes recién llegados- mostraron signos favorables hacia ellas. Para entonces, se habían revelado como un mecanismo de escasa utilidad, que no merecía la pena ser conservado y cuyos únicos frutos reseñables habían sido la creación de malestar entre los componentes de la administración peruana. Aun así, en manos únicas de Peńalosa, la visita continuó su curso dando unos últimos coletazos y demostrando que bien llevada podía revelar graves corrupciones.

Un informe entregado por el visitador el 15 de septiembre de 1696 da buena cuenta de ello. Peñalosa había sido acusado de compra-venta de inmuebles en la jurisdicción de su empleo, lo cual estaba expresamente prohibido en las Leyes de Indias, pero encontró justificación en su propio proceder como inspector. Peńalosa argumentó que la venta de una hacienda, que había sido propiedad del corrupto contador Sebastián de Navarrete, le había granjeado más de 30.000 pesos para utilizar en otras operaciones, pero que esto no debía tenérsele 
en cuenta por los resultados favorables que la Real Hacienda había obtenido por su trabajo. Según Peñalosa, el fisco regio había ingresado más de 470.000 pesos que les adeudaba el Consulado de Lima y otros 148.000 pesos correspondientes a tributos no cobrados. Razones suficientes para el visitador como para que se obviasen sus corruptelas. Además, presumió de haber terminado casi por completo una visita que a la fecha había cumplido treinta y dos años, y había entregado al Consejo de Indias y a la Audiencia una serie de documentos sobre las deudas que mantenía la Caja Real de Lima -unos 250.000 pesos aproximadamente- y los dańos que la mala gestión y la corrupción habían ocasionado en la institución (Andrien, 2011, p. 243).

\section{Consideraciones finales}

Más de tres décadas de visita, general y parcial, continuada en el virreinato del Perú no fueron capaces de dar como resultado un conocimiento exhaustivo de las prácticas que tenían lugar en el seno de la administración, corregir los defectos que se hallasen -más los consabidos por todos-, depurar cuantas instituciones mostrasen un rendimiento ineficaz o incluso negativo, eliminar a aquellos provistos y empleados que prestaban más interés a sus objetivos personales o clientelares que al servicio de la república y la Corona, entre otros.

La concatenación de diferentes responsables demostró que el proceso resultaba más complicado que lo previamente supuesto. Aun así, el deseo de auditar las instituciones peruanas fue más fuerte que el pragmatismo de cancelar una inspección que, dados los resultados que llegaban a la corte, se mostraba yerma. Por ello, el constante deseo de las autoridades metropolitanas se tradujo en el nombramiento suce- 
sivo de diferentes individuos que habrían de llevar a cabo la visita, sin casi reparar, salvo excepciones comentadas, en la idoneidad del propuesto o en sus capacidades para incidir positivamente en el proceso. A esta cuestión vino a añadírsele el importante componente de los intereses individuales y colectivos de los diferentes visitadores. Tal y como había ocurrido con las leyes que pretendieron el aislamiento social de los magistrados de las Audiencias indianas, desde la península ibérica se pretendió, al menos desde el punto de vista teórico, que los inspectores fuesen sujetos ajenos a todo el entramado que conformaban las instituciones y sus miembros. Este fue, como sabemos, un deseo imposible de llevar a la práctica, máxime cuando algunos de los visitadores analizados fueron extraídos del propio seno de esas corporaciones y, por tanto, impregnados de diferentes intereses, positivos o negativos, para las repúblicas de españoles e indios.

En definitiva, tal y como se ha apuntado, la visita demostró en la segunda mitad del siglo XVII ser un procedimiento ineficaz, falto de renovación e incapaz de frenar la corrupción. Una situación ante la que las autoridades metropolitanas no supieron dar respuesta, pero que tampoco se quiso enmendar desde el suelo peruano para así conservar el grado de autonomía factual que habían alcanzado algunos servidores de la Corona por estar a grandísima distancia de su control directo.

\section{Recibido: 16 de octubre de 2018}

Aprobado: 08 de abril de 2019 


\section{Referencias bibliográficas}

Andrien, K. J.

(2011) Crisis y decadencia. El virreinato de Perú en el siglo XVII. Lima: Banco Central de la Reserva de Perú, Instituto de Estudios Peruanos.

Andújar Castillo, F., Feros A. y Ponce Leiva, P.

(2017) Corrupción y mecanismos de control en la monarquía hispánica: una revisión crítica. Tiempos Modernos (35), 284-311.

Basadre Grohmann, J.

(1939) Don Álvaro de Ybarra y la Universidad de San Marcos. Letras (12), 5-30.

Céspedes del Castillo, G.

(1946) La visita como institución indiana. Anuario de Estudios Americanos, t. III, 984-1025.

Escobedo Mansilla, R.

(1986)

Control fiscal en el virreinato peruano. El Tribunal de Cuentas. Madrid: Ed. Alhambra.

Glave Testino, L. M.

(1989) Trajinantes. Caminos indigenas en la sociedad colonial, siglos XVI-XVII. Lima: Instituto de Apoyo Agrario.

Hanke, L. y Rodríguez, C.

(1980) Los virreyes españoles en América durante el gobierno de la casa de Austria, Madrid: Ed. Atlas (vol. V y VII).

Herzog, T.

(1997) La presencia ausente: el virrey desde la perspectiva de las élites locales (Audiencia de Quito, 1670-1747). En P. Fernández Albadalejo, (Coord.). Monarquía, imperio y pueblos en la España moderna. Alicante: Caja de Ahorros del Mediterráneo y Universidad de Alicante. 
Jiménez Jiménez, I.

(2013) Don Álvaro de Ybarra: el criollo más poderoso de su tiempo (1621-1675). En B. Cava Mesa, (Ed.). América en la memoria: conmemoraciones y reencuentros ( $\mathrm{t}$. II). Bilbao: Universidad de Deusto y Asociación Espańola de Americanistas.

Jiménez Jiménez, I.

(2015) Una herramienta inútil. Juicios de residencia y visitas en la Audiencia de Lima a finales del siglo XVII. Temas americanistas, (35), 60-87.

Jiménez Jiménez, I.

(2015b) Un virreinato 'sin virrey': el Perú y sus poderes político-económicos en tiempos del conde de Santisteban (1661-1666). Fronteras de la Historia, (20-1), 70-94.

Jiménez Jiménez, I.

(2016) Economía y urgencia fiscal: los asientos hacendísticos del Consulado de Lima en la segunda mitad del siglo XVII. Histórica, XL-1, 35-63. https://doi. org/10.18800/historica.201601.002

Lohmann Villena, G.

(1946) El conde de Lemos. Virrey del Perú. Madrid: Escuela de Estudios Hispanoamericanos.

Lohmann Villena, G.

(1957) El corregidor de indios en el Perú bajo los Austrias. Madrid: Ediciones Cultura Hispánica.

Lohmann Villena, G.

(1974) Los ministros de la Audiencia de Lima en el reinado de los Borbones (1700-1821). Sevilla: Escuela de Estudios Hispanoamericanos.

Mariluz Urquijo, J. M.

(1952) Ensayo sobre los juicios de residencia indianos. Sevilla:

Escuela de Estudios Hispanoamericanos. 
Muro Orejón, F.

(1982) La reforma del pacto colonial en las Indias. Notas sobre instituciones de gobierno y sociedad en el siglo XVII. Jahrbuch für Geschichte Lateinamerikas, (19), 47-68.

Phelan, J. L.

El reino de Quito en el siglo XVII. La politica burocrática en el imperio español. Quito: Banco Central de Ecuador.

Ponce Leiva, P.

(2016) Percepciones sobre la corrupción en la monarquía hispánica, siglos XVI y XVII. En P. Ponce Leiva y F. Andújar Castillo, F. (Eds.). Mérito, venalidad y corrupción en España y América. Siglos XVII y XVIII. Valencia: Editorial Albatros.

Sánchez Bella, I.

(1950) Eficacia de la visita en Indias. Anuario de Historia del Derecho Español, (50), 83-411.

Smietniansky, S.

(2007) El juicio de residencia como ritual político en la colonia (gobernación de Tucumán, siglo XVIII). Memoria Americana, (15), 71-101.

Tau Anzoátegui, V.

(1986) La costumbre jurídica en la América española (siglos XVI-XVIII). Revista de Historia del Derecho, (14), $355-425$. 